\title{
Global warming and recurrent mass bleaching of corals
}

Terry P. Hughes ${ }^{1}$, James T. Kerry ${ }^{1}$, Mariana Álvarez-Noriega ${ }^{1,2}$, Jorge G. Álvarez-Romero ${ }^{1}$,

Kristen D. Anderson ${ }^{1}$, Andrew H. Baird ${ }^{1}$, Russell C. Babcock ${ }^{3}$, Maria Beger ${ }^{4}$, David R.

Bellwood $^{1,2}$, Ray Berkelmans ${ }^{5}$, Tom C. Bridge ${ }^{1,6}$, Ian Butler ${ }^{7}$, Maria Byrne ${ }^{8}$, Neal E. Cantin ${ }^{9}$,

Steve Comeau ${ }^{10}$, Sean R. Connolly ${ }^{1,2}$, Graeme S. Cumming ${ }^{1}$, Steven J. Dalton ${ }^{11}$, Guillermo

Diaz-Pulido $^{12}$, C. Mark Eakin ${ }^{13}$, Will F. Figueira ${ }^{15}$, James P. Gilmour ${ }^{16}$, Hugo B. Harrison ${ }^{1}$,

Scott F. Heron ${ }^{13}{ }^{14,17}$, Andrew S. Hoey ${ }^{1}$, Jean-Paul A. Hobbs ${ }^{18}$, Mia O. Hoogenboom ${ }^{1,2}$,

Emma V. Kennedy ${ }^{12}$, Chao-yang Kuo ${ }^{1}$, Janice M. Lough ${ }^{1,9}$, Ryan J. Lowe $^{10}$, Gang Liu ${ }^{13,14}$,

Malcolm T. McCulloch ${ }^{10}$, Hamish A. Malcolm ${ }^{11}$, Michael J. McWilliam¹ ${ }^{1}$, John M. Pandolfi ${ }^{7}$,

Rachel J. Pears ${ }^{19}$, Morgan S. Pratchett ${ }^{1}$, Verena Schoepf ${ }^{10}$, Tristan Simpson ${ }^{20}$, William J.

Skirving ${ }^{13,14}$, Brigitte Sommer ${ }^{7}$, Gergely Torda ${ }^{1,9}$, David R. Wachenfeld ${ }^{19}$, Bette L. Willis ${ }^{1,2}$ and Shaun K. Wilson ${ }^{21}$

${ }^{1}$ Australian Research Council Centre of Excellence for Coral Reef Studies, James Cook University, Townsville, QLD 4811, Australia

${ }^{2}$ College of Marine \& Environmental Sciences, James Cook University, Townsville,

Queensland 4811, Australia

${ }^{3}$ Commonwealth Science and Industry Research Organization, GPO Box 2583 Brisbane, Qld 4001, Australia

${ }^{4}$ School of Biology, University of Leeds, Leeds, LS2 9JT, UK

${ }^{5} 24$ Hanwood Court, Gilston QLD 4211

${ }^{6}$ Queensland Museum, 70-102 Flinders St, Townsville, QLD, 4810, Australia

${ }^{7}$ Australian Research Council, Centre of Excellence for Coral Reef Studies, School of

Biological Sciences, University of Queensland, Brisbane, QLD 4072, Australia 
${ }^{8}$ School of Medical Sciences, University of Sydney, NSW 2006, Australia

${ }^{9}$ Australian Institute of Marine Science, PMB 3, Townsville, Queensland 4810, Australia

${ }^{10}$ Australian Research Council Centre of Excellence in Coral Reef Studies, Oceans Institute and School of Earth and Environment, University of Western Australia, Western Australia 6009, Australia

${ }^{11}$ Fisheries Research, Department of Primary Industries, PO Box 4291, Coffs Harbour, NSW 2450, Australia

${ }^{12}$ School of Environment, and Australian Rivers Institute, Griffith University, Brisbane, QLD 4111, Australia

${ }^{13}$ Coral Reef Watch, U.S. National Oceanic and Atmospheric Administration, College Park, MD 20740, USA

${ }^{14}$ Global Science \& Technology, Inc., Greenbelt, MD 20770, USA

${ }^{15}$ School of Biological Sciences, University of Sydney, Sydney, NSW 2006, Australia

${ }^{16}$ Australian Institute of Marine Science, Indian Oceans Marine Research Centre, UWA, Crawley, WA 6009, Australia

${ }^{17}$ Marine Geophysical Laboratory, College of Science, Technology and Engineering, James Cook University, Townsville, QLD 4811, Australia

${ }^{18}$ Department of Environment and Agriculture, Curtin University, Perth, WA 6845, Australia ${ }^{19}$ Great Barrier Reef Marine Park Authority, PO Box 1379, Townsville, QLD 4810, Australia ${ }^{20}$ Torres Strait Regional Authority, PO Box 261, Thursday Island, QLD 4875, Australia

${ }^{21}$ Department of Parks and Wildlife, Kensington, Perth, WA 6151, Australia 
47 In 2015-2016, record temperatures triggered a pan-tropical episode of coral bleaching,

48 the third global-scale event since mass bleaching was first documented in the 1980s.

49 Here we examine how and why the severity of recurrent major bleaching events has

50 varied at multiple scales, using aerial and underwater surveys of Australian reefs

51 combined with satellite-derived sea surface temperatures. The distinctive geographic

52 footprints of recurrent bleaching on the Great Barrier Reef in 1998, 2002 and 2016 were

53 determined by the spatial pattern of sea temperatures in each year. Water quality and

54 fishing pressure had minimal effect on the unprecidented bleaching in 2016, suggesting

55 that local protection of reefs affords little or no resistance to extreme heat. Similarly,

56 past exposure to bleaching in 1998 and 2002 did not lessen the severity of bleaching in

57 2016. Consequently, immediate global action to curb future warming is essential to

58 secure a future for coral reefs. 
60

The world's tropical reef ecosystems, and the people who depend on them, are increasingly impacted by climate change ${ }^{1-7}$. Since the 1980 s, rising sea surface temperatures due to global warming have triggered unprecedented mass bleaching of corals, including three pan-tropical events in 1998, 2010 and 2015/16 ${ }^{1}$. Thermal stress during marine heatwaves disrupts the symbiotic relationship between corals and their algal symbionts (Symbiodinium) spp.), causing the corals to lose their color ${ }^{2-3}$. Bleached corals are physiologically damaged, and prolonged bleaching often leads to high levels of mortality ${ }^{5-8}$. Increasingly, individual reefs are experiencing multiple bouts of bleaching, as well the impacts of more chronic local stressors such as pollution and overfishing ${ }^{1-4}$. Our study represents a fundamental shift away from viewing bleaching events as individual disturbances to reefs, by focussing on three recurrent bleachings over the past 18 years along the 2,300 km length of the Great Barrier Reef, as well as the potential influence of water quality and fishing pressure on the severity of bleaching.

The geographic footprints of mass bleaching of corals on the Great Barrier Reef have varied strikingly during three major events in 1998, 2002 and 2016 (Fig. 1a). In 1998, bleaching was primarily coastal and most severe in the central and southern regions. In 2002, bleaching was more widespread, and affected offshore reefs in the central region that had escaped in $1998^{8}$. In 2016, bleaching was even more extensive and much more severe, especially in the northern, and to a lesser extent the central regions, where many coastal, mid-shelf and offshore reefs were affected (Fig. 1a, b). In 2016, the proportion of reefs experiencing extreme bleaching (>60\% of corals bleached) was over four times higher compared to 1998 or 2002 (Fig. 1f). Conversely, in 2016, only $8.9 \%$ of 1,156 surveyed reefs escaped with no bleaching, compared to $42.4 \%$ of 631 reefs in 2002 and $44.7 \%$ of 638 in 1998 . The cumulative, combined footprint of all three major bleaching events now covers almost the 
entire Great Barrier Reef Marine Park, with the exception of southern, offshore reefs (Fig. 1d).

\section{Explaining spatial patterns}

The severity and distinctive geographic footprints of bleaching in each of the three years can be explained by differences in the magnitude and spatial distribution of sea-surface temperature anomalies (Fig. 1a, b and Extended Data Table 1). In each year, 61-63\% of reefs experienced four or more Degree Heating Weeks (DHW, ${ }^{\circ} \mathrm{C}$-weeks). In 1998, heat stress was relatively constrained, ranging from 1-8 DHWs (Fig. 1c). In 2002, the distribution of DHW was broader, and 14\% of reefs encountered 8-10 DHWs. In 2016, the spectrum of DHWs expanded further still, with 31\% of reefs experiencing 8-16 DHWs (Fig. 1c). The largest heat stress occurred in the northern 1000 km-long section of the Great Barrier Reef. Consequently, the geographic pattern of severe bleaching in 2016 matched the strong north-south gradient in heat stress. In contrast, in 1998 and 2002, heat stress extremes and severe bleaching were both prominent further south (Fig. 1a, b). In 2016, severe bleaching (defined as an aerial score of $>30 \%$ of corals bleached) was correctly predicted by satellite-derived DHW in a statistical model, in 75\% of cases (Extended Data Fig. 1 and Extended Data Table 1), similar to the amount of spatial variation in bleaching explained by temperature stress in 1998 and $2002^{8}$.

The geographic pattern of bleaching also demonstrates how marine heatwaves can be ameliorated by local weather ${ }^{9}$, even during a global bleaching event. Arguably, southern reefs of the Great Barrier Reef would also have bleached in 2016 if wind, cloud cover, and rain from ex-Tropical Cyclone Winston had not rescued them ${ }^{10}$. Winston passed over Fiji on February $20^{\text {th }}$, when the southern Great Barrier Reef was only $1{ }^{\circ} \mathrm{C}$ cooler than the north. By March $6^{\text {th }}$, this disparity increased to $4^{\circ} \mathrm{C}$ (Extended Data Fig. 2). Corals in the south that had 
begun to pale in February regained their colour in the south in March, whereas bleaching continued to progress in central and northern sectors (Fig. 2a). Similarly, in western Australia in 2016, Tropical Cyclone Stan cooled down mid-coast regions in early February ${ }^{11}$, and the Leeuwin Current (which transports warm tropical water southwards) was also weakened due to El Niño conditions ${ }^{12}$. Consequently, both sides of tropical and sub-tropical Australia, including offshore atolls in the Coral Sea and Indian Ocean, exhibited continental-scale latitudinal gradients in bleaching (Fig. 1g).

The local (individual reef) scale pattern of recurrent bleaching on the Great Barrier Reef also reveals the trend of increasing severity, and the erosion of potential spatial refugia. Of the 171 individual reefs that were aerial-surveyed three times, $43 \%$ bleached in $1998,56 \%$ in 2002, and $85 \%$ in 2016. Knowing the bleaching-history of these well-studied reefs allows us to investigate why they have bleached zero, one, two or three times. Only $9 \%$ of these repeatedly surveyed reefs have never bleached, in most cases because they are located near the southern, offshore end of the Great Barrier Reef (Fig. 1e), where they have experienced relatively low temperature anomalies during each event. A further $26 \%$ of repeatedlysurveyed reefs have bleached only once - ten reefs in 1998, eight in 2002, and 32 for the first time in 2016. The latter were primarily in the northern sector of the Great Barrier Reef, which largely escaped bleaching in the two earlier events (Fig. 1a). Thirty-five percent of the reefs have bleached twice, but only one reef bleached in both 1998 and 2002, compared to 58 reefs that bleached either in 1998 or 2002 and for a second time in the severe 2016 event. Finally, $29 \%$ of the repeatedly censused reefs bleached for a third time in 2016, primarily in central areas of the Great Barrier Reef, because they experienced anomalously warm temperatures during all three events (Fig. 1b, e). We conclude that the overlap of disparate geographic footprints of heat stress explains why different reefs have bleached 0-3 times, i.e. the repeated exposure to unusually hot conditions is the primary driver of the likelihood of recurrent 
bleaching at the scale of both individual reefs and the entire Great Barrier Reef (Fig. 1a, b).

We found a similar strong relationship between the amount of bleaching measured underwater, and the satellite-based estimates of heat exposure on individual reefs (Fig. 3).

Low levels of bleaching was observed at some locations when DHW values were only 2-3 ${ }^{\circ} \mathrm{C}$-weeks. Typically, 30-40\% of corals bleached on reefs exposed to $4{ }^{\circ} \mathrm{C}$-weeks, whereas an average of $70-90 \%$ of corals bleached on reefs that experience $8{ }^{\circ} \mathrm{C}$-weeks or more (Fig. 3).

\section{Resistance and adaptation to bleaching}

Once we account for the amount of heat stress experienced on each reef, adding chlorophyll-a, a proxy for water quality, to our statistical model yielded no support for the hypothesis that good water quality confers resistance to bleaching ${ }^{13}$. Rather, the estimated effect of chlorophyll-a was to significantly reduce the DHW threshold for bleaching (Extended Data Table 1). However, despite the statistical significance, the effect in real terms beyond heat stress alone is very small (Extended Data Fig. 1). Similarly, we found no effect of the level of protection (in fished or protected zones) on bleaching $(\mathrm{P}>0.1$ : Extended Data Table 1). These results are consistent with the broad-scale pattern of severe bleaching in the northern Great Barrier Reef, which affected hundreds of reefs across inshore-offshore gradients in water quality, and regardless of their zoning (protection) status (Fig. 1a, b).

Similarly, we find no evidence for a protective effect of past bleaching (e.g. from acclimation or adaptation): reefs with higher bleaching scores in 1998 or 2002 did not experience less severe bleaching in 2016, after accounting for the relationship between the 2016 temperature stress and bleaching propensity $(\mathrm{P}>0.9$ in all cases; Extended Data Figure 3). Thus, while several studies have indicated that prior exposure can influence the subsequent bleaching responses of corals ${ }^{14-17}$, our comprehensive analysis of 171 repeatedly 
censused reefs indicates that any such historical effects on the Great Barrier Reef were masked by the severity of bleaching in 2016 (Fig. 2).

\section{Winners and losers}

Individual coral taxa bleached to different extents, especially on less affected reefs, creating both winners and losers, but the disparity among species diminished in the worst affected, northern regions. (Fig. 4). At the population and assemblage level, when and where bleaching is severe, even century-old corals can bleach (Fig. 2b-d). In contrast, where bleaching is less intense, it is highly selective, with a broad spectrum of responses shown by resistant corals (so-called winners) versus susceptible species (losers); winners by definition bleach less and have higher survivorship ${ }^{18-21}$. On lightly and moderately bleached reefs $(<10 \%$ or $10-30 \%$ of corals affected), predominantly in the southern Great Barrier Reef, many of the more robust coral taxa escaped with little or no bleaching in 2016. In contrast, on extremely bleached reefs in the north $(60-80 \%$ or $>80 \%$ overall bleaching), we found far fewer lightly-bleached winners (Fig. 4). The rank order of winners versus losers also changed as the severity of bleaching increased (Extended Data Table 2), reflecting disparate responses by each taxon to the range of bleaching intensities. Thus, even species that are winners on relatively mildly bleached reefs joined the ranks of losers where bleaching was more intense (Fig. 4), creating a latitudinal gradient in the response of the coral assemblages.

The recovery time for coral species that are good colonizers and fast growers is $10-15$ years ${ }^{22-}$ ${ }^{24}$, but when long-lived corals die from bleaching their replacement will necessarily take many decades. Recovery for long-lived species requires the sustained absence of another severe bleaching event (or other significant disturbance), which is no longer realistic while global temperatures continue to rise $\mathrm{e}^{25}$. Therefore, the assemblage structure of corals is now likely to be permanently shifted at severely bleached locations in the northern Great Barrier Reef. 


\section{Implications for reef management}

Our analysis has important implications for the management and conservation of coral reefs. We found that local management of coral reef fisheries and water-quality affords little if any resistance to recurrent severe bleaching events: even the most highly protected reefs and near-pristine areas are highly susceptible to severe heat stress. On the remote northern Great Barrier Reef, hundreds of individual reefs were severely bleached in 2016 regardless of whether they were zoned as no-entry, no-fishing, or open to fishing, and irrespective of inshore-offshore differences in water quality (Fig. 1a and Extended Data Fig. 1). However, local protection of fish stocks and improved water quality may, given enough time, improve the prospects for recovery ${ }^{3,4,26-29}$. A key issue for all coral reefs is the frequency, or return time, of recurrent disturbance events, and whether there is sufficient time between successive bleachings for the re-assembly of mature coral assemblages. The chances of the northern Great Barrier Reef returning to its pre-bleaching assemblage structure are slim given the scale of damage that occurred in 2016 and the likelihood of a fourth bleaching event occurring within the next decade or two as global temperatures continue to rise.

Identifying and protecting spatial refugia is a common strategy for conservation of threatened species and ecosystems, including coral reefs ${ }^{30}$. However, our analyses indicate that the cumulative footprint of recurrent bleachings is expanding, and the number of potential refugia on the Great Barrier Reef is rapidly diminishing. Indeed, the remote northern region escaped serious damage in 1998 and 2002, but bore the brunt of extreme bleaching in 2016. Rather than relying on the premise of refugia, our results highlight the growing importance of promoting the recovery of reefs to recurrent bleaching events through local management of marine parks and water quality. However, bolstering resilience will become more challenging and less effective in coming decades because local interventions have had no discernible effect on resistance of corals to extreme heat stress, and, with increasing frequency of severe 
207 bleaching events, the time for recovery is diminishing. Securing a future for coral reefs,

208 including intensively managed ones such as the Great Barrier Reef, ultimately requires urgent 209 and rapid action to reduce global warming. 


\section{References}

1. Heron, S. F., Maynard, J. A., van Hooidonk, R. \& Eakin, C. M. Warming trends and bleaching stress of the World's coral reefs 1985-2012. Scientific Reports 6, 38402 (2016)

2. Spalding, M. D. \& Brown, B. E. Warm-water coral reefs and climate change. Science 350, 769-771 (2015).

3. Baker, A. C., Glynn, P. W. \& Riegl, B. Climate change and coral reef bleaching: An ecological assessment of long-term impacts, recovery trends and future outlook. Estuar. Coast. Shelf Sci. 80, 435-471 (2008).

4. Hughes, T. P. et al. Climate change, human impacts, and the resilience of coral reefs. Science 301, 929-933 (2003).

5. Glynn, P. W. Widespread coral mortality and the 1982-83 El Nino Warming Events. Environ. Conser. 11, 133-146 (1984).

6. Oliver, J. K., Berkelmans, R. \& Eakin, C. M. in Ecological Studies: Analysis and Synthesis (M. J. H. van Oppen \& J. M. Lough eds.) 21-39 (2009).

7. Eakin, C. M. et al. Global Coral Bleaching 2014-2017. Reef Currents 31, 1 (2016).

8. Berkelmans, R., De'ath, G., Kininmonth, S. \& Skirving, W. J. A comparison of the 1998 and 2002 coral bleaching events on the Great Barrier Reef: spatial correlation, patterns, and predictions. Coral Reefs 23, 74-83 (2004).

9. Carrigan, A. D. \& Puotinen, M. Tropical cyclone cooling combats region-wide coral bleaching. Global Change Biol. 20, 1604-1613 (2014).

10. Leahy, S. M., Kingsford, M. J, \& Steinberg, C. R. Do clouds save the Great Barrier Reef? Satellite imagery elucidates the cloud-SST relationship at the local scale. Plos One 8, e70400 (2013). 
11. Australian Bureau of Meteorology (BOM). Tropical Cyclone Stan Track. http://www.australiasevereweather.com/cyclones/2016/bom/tropical_cyclone_stan.pn g (2016).

12. Feng, M., Meyeres, G., Pearce, A. \& Wijffels, S. Annual and interannual variations of the Leeuwin Current at $32^{\circ}$ S. J. Geophys. Res. 108, 2156-2202 (2003).

13. Wooldridge, S. A., et al. Excess seawater nutrients, enlarged algal symbiont densities and bleaching sensitive reef locations: 2 . A regional-scale predictive model for the Great Barrier Reef, Australia. Mar. Pollut. Bull. 10.1016/j.marpolbul.2016.09.045 (2016).

14. Carilli, J., Donner, S. D. \& Hartmann, A. C. Historical temperature variability affects coral response to heat stress. PloS One 7, e34418 (2012).

15. Guest, J. R. et al. Contrasting patterns of coral bleaching susceptibility in 2010 suggest an adaptive response to thermal stress. PLoS One 7, e33353 (2012).

16. Pratchett, M. S., McCowan, D., Maynard, J. A. \& Heron, S. F. Changes in bleaching susceptibility among corals subject to ocean warming and recurrent bleaching in Moorea, French Polynesia. PLoS One 8, e70443 (2013).

17. Ainsworth, T. D. et al. Climate change disables coral bleaching protection on the Great Barrier Reef. Science 352, 338-342 (2016).

18. Loya, Y. et al. Coral bleaching: the winners and the losers. Ecol. Lett. 4, 122-131 (2001).

19. Swain, T. D. et al. Coral bleaching response index: a new tool to standardize and compare susceptibility to thermal bleaching. Glob. Chan. Biol. 22, 2475-2488 (2016).

20. Baird, A. H. \& Marshall, P. A. Mortality, growth and reproduction in scleractinian corals following bleaching on the Great Barrier Reef. Mar. Ecol. Prog. Ser. 237, 133$141(2002)$. 
21. Marshall, P. A. \& Baird, A. H. Bleaching of corals on the Great Barrier Reef: differential susceptibilities among taxa. Coral Reefs. 19, 155-163 (2000).

22. Connell, J. H., Hughes, T. P. \& Wallace, C. C. A 30-year study of coral community dynamics: Influence of disturbance and recruitment on abundance, at several scales in space and time. Ecol. Monogr. 67, 461-488 (1997).

23. Kayanne, H., Harii, S., Ide, Y. \& Akimoto, F. Recovery of coral populations after the 1998 bleaching on Shiraho Reef, in the southern Ryukyus, NW Pacific. Mar. Ecol. Prog. Ser. 239, 93-103 (2002).

24. Gilmour J. P., Smith, L. D., Heyward, A. J., Baird, A. H. \& Pratchett, M. S. Recovery of an isolated coral reef system following severe disturbance. Science 340, 69-71 (2013).

25. van Hooidonk, R. et al. Local-scale projections of coral reef futures and implications of the Paris Agreement. Scientific Reports (in press).

26. Scheffer, M. et al. Creating a safe operating space for iconic ecosystems. Science 347, 1317-1319 (2015).

27. van de Leemput, I. A., Hughes, T. P., van Nes, E. H. \& Scheffer, M. Multiple feedbacks and the prevalence of alternate stable states on coral reefs. Coral Reefs $\mathbf{3 5}$, 857-865 (2016).

28. Hughes, T. P., Graham, N. A. J., Jackson, J. B. C., Mumby, P. J. \& Steneck, R. S. Rising to the challenge of sustaining coral reef resilience. Trends Ecol. Evol. 25, 633$642(2010)$.

29. Graham, N., Jennings, S., Macneil. M. A., \& Mouillot, D. Predicting climate-driven regime shifts versus rebound potential in coral reefs. Nature 518, 94-97 (2015).

30. West, J. M. \& Salm, R. V. Resistance and resilience to coral bleaching: implications for coral reef conservation and management. Conserv. Biol. 17, 956-967 (2003). 
Acknowledgements The authors acknowledge the 23 institutions that supported this research, in Australia, Canada, UK, Saudi Arabia and the USA. Twenty-six of the authors are supported by funding from the Australian Research Council's Centre of Excellence Program. Other funding support includes the Australian Commonwealth Government, the European Union, the USA National Oceanographic \& Atmospheric Administration, and USA National Science Foundation. The contents in this manuscript are solely the opinions of the authors and do not constitute a statement of policy, decision or position on behalf of NOAA or the U.S. Government. We thank 43 colleagues who provided coral bleaching records for their field sites, and 30 student volunteers who participated in field and laboratory studies in 2016.

Author contributions The study was conceptualized by TPH who wrote the first draft of the paper. All authors contributed to writing subsequent drafts. JTK coordinated data compilation, analysis and graphics. Aerial bleaching surveys in 2016 of the Great Barrier Reef and Torres Strait were executed by JTK, TPH and TS, and in 1998 and 2002 by RB and DRW. Underwater bleaching censuses in 2016 were undertaken on the Great Barrier Reef by MAN, AHB, DRB, MB, NEC, CYK, GDP, ASH, MOH, EVK, MMcW, RJP, MSP, GT and BLW, in the coral Sea by TCB and HBH, in subtropical Queensland and New South Wales by MB, IRB, RCB, SJD, WFF, HAM, JMP, and BS, off western Australia by RCB, SC, JPG, JPH, MMcC, VS and SKW. JGA-R, SRC, CME, SFH, GL, JML, and WJS undertook the analysis matching satellite data to the bleaching footprints on the Great Barrier Reef

Author information Reprints and permissions information is available at www.nature.com/reprints. The authors declare no competing financial interests. Readers are welcome to comment on the online version of the paper. Correspondence and requests for materials should be addressed to T.P.H. (terry.hughes@jcu.edu.au) 
Figure 1. Geographic extent and severity of recurrent coral bleaching at a regional scale, Australia. (a) The footprint of bleaching on the Great Barrier Reef in 1998, 2002 and 2016, measured by extensive aerial surveys: dark green ( $<1 \%$ of corals bleached), light green (1$10 \%)$, yellow (10-30\%), orange (30-60\%), red (>60\%). The number of reefs surveyed in each year was 638 (1998), 631 (2002), and 1,156 (2016). (b) Spatial pattern of heat stress (Degree Heating Weeks, DHWs, ${ }^{\circ} \mathrm{C}$-weeks) during each mass bleaching event. (c) Frequency distribution of maximum DHWs on the Great Barrier Reef, in 1998, 2002 and 2016. White bars indicate $0-4{ }^{\circ} \mathrm{C}$-weeks, grey bars $4-8{ }^{\circ} \mathrm{C}$-weeks, black bars $>8{ }^{\circ} \mathrm{C}$-weeks. (d) Locations of individual reefs that bleached (by $>10 \%$ or more) in 1998, 2002 and/or 2016, showing the most severe bleaching score for reefs that were censused more than once. Yellow (10-30\% bleaching), Orange (30-60\%), Red (>60\%). (e) Location of reefs that were censused in all three years that bleached zero (white), one (light grey), two (dark grey) or three times (black).

(f) Frequency distribution of aerial bleaching scores for reefs surveyed in 1998 (left bar), 2002 (middle), and 2016 (right). Colour bleaching scores as in (a). (g) Bleaching severity during March to early April 2016 on both sides of Australia, including the Coral Sea and the eastern Indian Ocean. Colour bleaching scores as in (a). Bar graphs show mean sea-surface temperatures during March for each year from 1980 to 2016 for northern and southern latitudes on either side of Australia. The red bar highlights the north-south disparity in 2016.

Figure 2. Recurrent severe coral bleaching. (a) Aerial view of severe bleaching in Princess Charlotte Bay, NE Australia, March 2016. Close to 100\% of corals are bleached on the reef flat and crest. Bleaching occurs when algal symbionts (Symbiodinium spp.) in a coral host are killed by environmental stress, revealing the white underlying skeleton of the coral. (b) Severe bleaching in 2016 on the northern Great Barrier Reef affected even the largest and 
corals, Acropora pulchra, on Orpheus Island, Queensland photographed in 1997 were killed by the first major bleaching event on the Great Barrier Reef in 1998. (d) Eighteen years later in May 2016, corals at this site have never recovered, with the original assemblages still visible as dead, unconsolidated and muddy rubble that is unsuitable for successful colonization by coral larvae. (e-f) Mature stands of clonal staghorn corals were extirpated by heat stress and colonized by algae over a period of just a few weeks in 2016 on Lizard Island, Great Barrier Reef. Before (e) and after (f) photographs were taken on February $26^{\text {th }}$ and April 19 ${ }^{\text {th }}$ 2016. Photo credits: (a) JTK, (b) J. Marshall, (c) BW, (d) AHB, (e-f) R. Streit.

Figure 3. The relationship between heat exposure (satellite-based Degree Heating Weeks in 2016) and the amount of bleaching measured underwater (percent of corals bleached) in March/April. Each data point represents an individual reef $(n=69)$. The fitted line is $y=$ $48.6 \ln (\mathrm{x})-21.6, \mathrm{R}^{2}=0.545$.

Figure 4. Spectrum of bleaching responses by coral taxa on the Great Barrier Reef in 2016, with relative winners on the right, and losers on the left. Species or genera (58,414 colonies) are plotted in rank descending order along the $\mathrm{x}$-axis from high to low levels of impact, for reefs that are lightly bleached (bottom spectrum) or more severely bleached (top). Reef-scale bleaching severities are (blue) 1-10\% of all corals bleached, (green) 10-30\%, (yellow) 30$60 \%$, (orange) $60-80 \%$, and (red) $>80 \%$ bleached. See Extended Data Table 2 for taxonomic details. 


\section{Methods}

\section{Recurrent bleaching on the Great Barrier Reef}

For 2016, comprehensive aerial surveys of the Great Barrier Reef Marine Park and Torres Strait reported in Fig. 1a were conducted on ten days between $22^{\text {nd }}$ March 2016 and $17^{\text {th }}$ April 2016 when bleaching was highly visible. We used light aircraft and a helicopter, flying at an elevation of approximately $150 \mathrm{~m}$. A total of 1,156 individual reefs from the coast to the edge of the continental shelf were assessed along $14^{\circ}$ of latitude (Extended Data Fig. 4). Each reef was assigned by visual assessment to one of five categories of bleaching severity, using the same protocols as earlier aerial surveys conducted in 1998 and 2002 by $\mathrm{RB}^{8}$ : (0) less than $1 \%$ of corals bleached, (1) $1-10 \%$, (2) $10-30 \%$, (3) 30-60\%, and (4) more than $60 \%$ of corals bleached. The accuracy of the scores was assessed by underwater ground-truthing (see next section). The aerial scores are presented in Fig. 1a as heat-maps (Stretch type: MinimumMaximum) using inverse distance weighting (IDW; Power: 2, Cell Size: 1000, Search Radius: variable, 100 points) in ArcGIS 10.2.1.

\section{Underwater surveys of eastern and western Australia}

To ground-truth the accuracy of aerial scores of bleaching on the Great Barrier Reef (Fig. 1a), we conducted in-water surveys on 104 reefs during March and April 2016 (Extended Data Fig. 5). We also measured differential species responses (winners-losers; Fig. 4) on 83 reefs, spanning the $1200 \mathrm{~km}$ long central and northern Great Barrier Reef, from 10-19 $\mathrm{S}$. We surveyed two sites per reef, using five $10 \times 1 \mathrm{~m}$ belt transects placed on the reef crest at a depth of $2 \mathrm{~m}$ at each site. Observers identified and counted each coral colony and recorded a categorical bleaching score for each individual: (1) no bleaching, (2) pale, (3) 1-50\% bleached, (4) 51-99\% bleached, (5) 100\% bleached, (6) bleached and recently dead. The sitelevel amount of bleaching for each taxon in Figure 4 is the sum of categories 2-5. The 
number of colonies assessed was 58,414. A similar standardised protocol was used to measure amounts of bleaching for the Coral Sea, on sub-tropical reefs south of the Great Barrier Reef, and across 18 degrees of latitude along the west coast of Australia (Fig. 1g).

\section{Temperature and Thermal Stress}

The spatial pattern of thermal stress on the Great Barrier Reef during each of the three major bleaching events (1998, 2002 and 2016; Fig. 1b, c) was quantified using the well-established Degree Heating Week (DHW) metric ${ }^{31}$. The DHW values were calculated using the Optimum Interpolation Sea Surface Temperature $(\mathrm{OISST})^{32}$, because it provides a consistent measure of thermal stress for all three major bleaching events on the Great Barrier Reef. The baseline climatology for the DHW metric was calculated for 1985-2012, following Heron et al. ${ }^{33}$. DHW values are presented in Fig. 2b as heat-maps (Stretch type: Minimum-Maximum) using inverse distance weighting (IDW; Power: 2, Cell Size: 1000, Search Radius: variable, 100 points) in ArcGIS 10.2.1. For Fig. 2g, March temperatures were compiled from HadISST $1^{34}$ from 1980-2016 for four regions: northwest Australia, 10.5-20.5 ${ }^{\circ}$; mid-west 20.5-30.5 ${ }^{\circ}$; northern Great Barrier Reef $\left(10.5^{\circ} \mathrm{S}-16.5^{\circ} \mathrm{S}\right)$, and southern Great Barrier Reef $\left(21.5^{\circ} \mathrm{S}-24.5^{\circ} \mathrm{S}\right)$

\section{Water Quality Metrics}

We considered remotely-sensed chlorophyll-a and secchi depth proxies as water quality metrics, measured for the Great Barrier Reef ${ }^{35}$ over different averaging windows.

Specifically, we used four averaging windows with respect to $2016(1,2$, or 4 years prior to bleaching, and a long term 1997-2016 average), and two different time periods (summer months only [December through May] and the entire year [June through May]). We also considered derived quantities from these estimates: the proportion of time that reefs exceeded an estimated water quality chlorophyll-a threshold of $0.45 \mu \mathrm{g} / \mathrm{L}^{13}$ and secchi depth exposure, 
401

402

403

404

405

406

407

408

409

410

411

412

413

414

415

416

417

418

419

420

421

422

again for four different averaging windows, and for the full year and for summer only. All of these metrics were significantly correlated with one another. In particular, long-term (19972016) average chlorophyll-a concentration was very highly correlated with all other metrics (absolute value of Spearman's rank correlation coefficient averaged $\mathrm{r}=0.81$, and was never lower than 0.7). Therefore, to minimize the risk of Type I error, we used it as the water quality proxy in our analyses of bleaching, log-transformed to obtain a symmetric distribution of values.

\section{Analysis of spatial patterns, resistance and adaptation}

To model the factors affecting bleaching in 2016, we used aerial bleaching scores as a response variable; whether a reef was severely bleached (57\% of reefs had a bleaching score of 3-4) or not (the remaining 43\% of reefs had a bleaching score of 0-2), for all surveyed reefs in the Great Barrier Reef Marine Park. We considered temperature stress (measured as DHW, described above), water quality (measured as the natural logarithm of long-term chlorophyll-a concentration), and marine protection status. Reefs in three zones classified as Marine National Park, Preservation, Scientific Research, and Buffer were considered to be Protected in the model, whereas all other zones were Fished. We repeated our test using other splits of bleaching scores ( 0 versus 1-4, 0-1 versus 2-4, and 0-3 versus 4), although these led to more uneven splits of the data. Regardless of how the bleaching scores were binned, the severity of bleaching was significantly correlated with DHW, while the additional variables had effects that were similar to our original analysis: small in magnitude or statistically nonsignificant.

To calibrate the relationship between temperature and bleaching, we fit a generalized linear model (GLM) with binomial error structure, using Degree Heating Weeks (DHW) as the explanatory variable. To test the hypothesis that high water quality confers bleaching 
425 resistance ${ }^{13}$, we fit a model including both DHW and chlorophyll-a as explanatory variables,

426 and asked whether the effect of chlorophyll-a concentration was significantly positive (that

427 is, if reefs with higher chlorophyll-a concentrations had a higher probability of bleaching).

428 Similarly, to test the hypothesis that fishing increases bleaching resistance, we fit a model

429 including DHW and protection status as explanatory variables, and asked whether the effect

430 of protection was significantly negative (Protected reefs had a lower probability of bleaching,

431 at a given level of temperature stress, than Fished reefs, see Extended Data Fig. 1 and

432 Extended Data Table 1).

433 To test for evidence of acclimation or adaptation, we extracted the residuals from our DHW-

434 only generalized linear model (Extended Data Table 1), and we tested for a negative

435 correlation between the residuals and the aerial bleaching scores recorded during prior events:

4361998 , 2002, or the higher of the two earlier scores (Extended Data Fig. 1). That is, we tested

437 the hypothesis that reefs that bleached more severely in prior events were less likely to bleach

438 at a given temperature stress in 2016, compared to reefs that bleached less in prior events.

439 Because bleaching score is ordered and categorical, we tested this hypothesis with Kendall's

440 tau.

\section{Methods References}

442 31. Eakin, C. M. et al. Caribbean Corals in Crisis: Record Thermal Stress, Bleaching, and Mortality in 2005. PloS One 5, e13969 (2010).

32. Reynolds, R. W. et al. Daily high-resolution-blended analyses for sea surface temperature. J. Clim. 20, 5473-5496 (2007).

33. Heron, S.F., et al. Climatology development for NOAA Coral Reef Watch's 5-km product suite. 30 (NOAA Technical Report NESDIS 145. NOAA/NESDIS. doi:10.7289/V59C6VBS, 2014). 
449

450

451

452

453

454

455

456

Data and code available on request from the authors. (2003).

http://hermes.acri.fr/n (2016).

Data and code availability

34. Rayner, N. et al. Global analyses of sea surface temperature, sea ice, and night marine air temperature since the late nineteenth century. J. Geophys. Res. D 108, 4407

35. Globcolour. Remotely-sensed chlorophyll concentration $\left(\mathrm{mg} / \mathrm{m}^{3}\right)$ and Secchi Disk depth (m) based on Sea-Viewing Wide Field of View Sensor (SeaWIFS) imagery. 


\section{Extended Data Figure Legends}

Extended Data Figure 1. A General Linear Model to explain the severity of coral bleaching.

Curves show the estimated relationships between probability of severe bleaching (>30\%) on individual reefs of the Great Barrier Reef in 2016 and three explanatory variables (Degree Heating Weeks, chlorophyll-a, and Reef Zoning, see Extended Data Table 1): The DHWonly model is shown in black. For the DHW plus chlorophyll-a model, the blue threshold shows the estimated relationship between probability of severe bleaching and DHW for the $25^{\text {th }}$ percentile of chlorophyll-a, and the brown threshold shows the same for the $75^{\text {th }}$ percentile of chlorophyll-a. For the DHW plus Reef Zoning model, the red threshold, shows the relationship for fished reefs, and the green for unfished reefs. Water quality metrics and level of reef protection make little if any difference.

Extended Data Figure 2. Difference in daily sea surface temperatures between the northern and southern Great Barrier Reef, before and after ex-Tropical Cyclone Winston. The disparity between Lizard Island $\left(14.67^{\circ} \mathrm{S}\right)$ and Heron Island $\left(23.44^{\circ} \mathrm{S}\right)$ increased from $1^{\circ} \mathrm{C}$ in late February to $4^{\circ} \mathrm{C}$ in early March, 2016.

Extended Data Figure 3. A test for the effect of past bleaching experience on the severity of bleaching in 2016. The relationship between previous bleaching scores (in 1998 or 2002 , whichever was higher) and the residuals from the DHW generalized linear model (Extended Data Table 1). Each data point represents an individual reef that was scored repeatedly. There is no negative relationship to support acclimation or adaptation.

Extended Data Figure 4. Flight tracks of aerial surveys of coral bleaching, conducted along and across the Great Barrier Reef and Torres Strait in March and April 2016.

Extended Data Figure 5. Ground-truthing comparisons of aerial and underwater bleaching scores. Aerial scores are: 0 ( $<1 \%$ of colonies bleached), 1 (1-10\%), $2(10-30 \%), 3(30-60 \%)$ 
482

483

484

485

486

487

488

489

490

491

492

493

494

495

496

497

and $4(60-100 \%)$ on the Great Barrier Reef in 2016 (Fig. 1a). Continuous (0-100\%)

underwater scores are based on in situ observations from 259 sites (104 reefs). Error bars indicate two standard errors above and below the median underwater score, separately for each aerial category. The dashed horizontal grey lines show the upper and lower boundaries of each bleaching category.

Extended Data Table 1. A test for the causes of coral bleaching. Generalized linear models (GLM) show the relationship between severe bleaching of reefs (>30\%) in 2016 on the Great Barrier Reef and three explanatory variables. Explanatory variables were (A) Degree Heating Weeks (DHW), (B) DHW plus water quality (natural logarithm of chlorophyll-a concentration), and (C) DHW plus reef zoning (Protected or Fished). Note that the estimated effect of chlorophyll-a is negative, contrary to the hypothesis that good water quality confers resistance to bleaching.

\section{Extended Data Table 2.}

Winners and losers. Rank order of taxa, from most bleached to least bleached, for different severities of bleaching. See Fig. 4. 